\title{
Strengthening the financial sustainability of two Population Services and Training Center (PSTC) clinics (Bangladesh)
}

Population Services and Training Center (PSTC)

Frontiers in Reproductive Health

Follow this and additional works at: https://knowledgecommons.popcouncil.org/departments_sbsr-rh

Part of the Health Services Research Commons, International Public Health Commons, Maternal and Child Health Commons, and the Social and Behavioral Sciences Commons How does access to this work benefit you? Let us know!

\section{Recommended Citation}

Population Services and Training Center (PSTC) and Frontiers in Reproductive Health. 2008.

"Strengthening the financial sustainability of two Population Services and Training Center (PSTC) clinics (Bangladesh)," FRONTIERS Final Report. Washington, DC: Population Council. 


\title{
Strengthening the Financial Sustainability of Two Population Services and Training Center (PSTC) Clinics
}

\author{
Population Services and Training Center (PSTC) \\ Dhaka, Bangladesh
}

\section{September 2008}

This study was made possible by the generous support of the American people through the United States Agency for International Development (USAID) under the terms of Cooperative Agreement Number HRN-A-00-98-00012-00 and Subagreement number AI05.61A. The contents are the responsibility of the Population Council and do not necessarily reflect the views of USAID or the United States Government. 


\section{EXECUTIVE SUMMARY}

The Population Services and Training Center of Bangladesh (PSTC) operates 15 clinics and 150 satellite posts that provide an Essential Services Package (ESP) to the poor, consisting of child health, family planning, maternal health, communicable disease treatment, and limited curative care. Nominal fees are paid for these services that cannot sustain services. Donors requested that PSTC reduce dependency on external financial support by increasing cost recovery, while the Government of Bangladesh (GOB) restricted PSTC's right to collect service fees for vaccination (EPI), tetanus toxoid (TT), and family planning (FP) services.

The objective of this study was to conduct an operations research (OR) study to determine the feasibility of improving cost recovery in two clinics by raising prices Cost and income information were to be collected during the study. A willingness to pay survey (WTP) was conducted prior to the price increase to estimate feasible price increase levels.

Collection of cost data could not be completed as planned as estimation of costs had serious validity problems. Consequently, the WTP survey did not obtain the required number of interviews. Widespread exoneration of fees was practiced by the clinics without proper documentation, thus the impact of price increases on demand could not be judged. The study was not implemented correctly and so the results cannot be considered valid.

It appears that the study design was too ambitious for PSTC, a service delivery organization with no prior research experience. Lack of experience was compounded by the resignation of all three PSTC research staff during the study, and by turnover of economists providing technical assistance from FRONTIERS staff at Population Council/India and Family Health International. 


\section{TABLE OF CONTENTS}

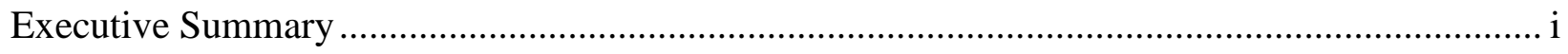

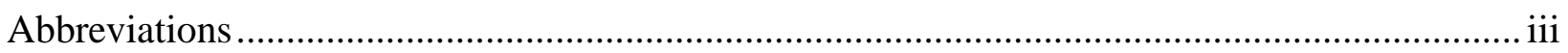

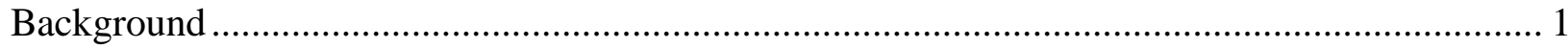

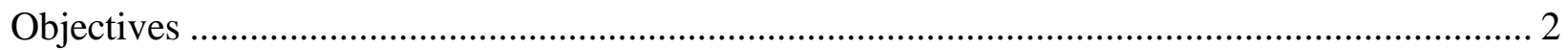

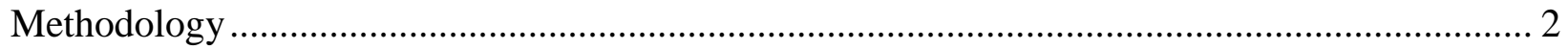

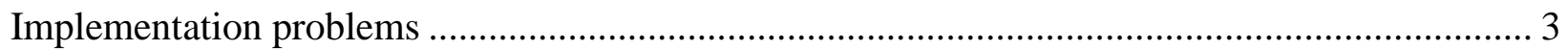

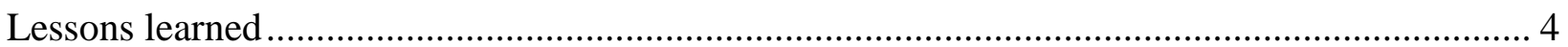




\section{ABBREVIATIONS}

AVC

BCG

DPT

EPI

ESP

GOB

NGO

NSDP

OR

PSTC

RA

STI

RTI

TT

USAID
Average Variable Cost

Bacille Calmette-Guérin

Diphtheria, Pertussis and Tetanus

Expanded Program on Immunization

Essential Service Package

Government of Bangladesh

Non Governmental Organization

National Service Delivery Program

Operations Research

Population Services and Training Center

Research Assistant

Sexually Transmitted Infections

Reproductive Tract Infection

Tetanus Toxoid

United States Agency for International Development 


\section{BACKGROUND}

One of the key activities of the Frontiers in Reproductive Health (FRONTIERS) project was to train and help NGOs build their capacity to use operations research (OR) techniques and financial analysis to make programmatic decisions designed to reduce donor dependency. A regional workshop was held in India in 2004, at which NGOs from Bangladesh, India and Nepal developed OR proposals that were subsequently funded by FRONTIERS. Technical assistance was provided by Family Health International (FHI) to help design protocols and carry out the research.

One of the workshop participants was the Population Services and Training Center (PSTC) in Bangladesh. The Population Services and Training Centre (PSTC) is one of the largest NGOs in Bangladesh working in population and development. Its Family Health Project operates 15 clinics and 150 satellite posts reaching a population of approximately one million. With financial support from USAID, PSTC is primarily responsible for the provision of an Essential Services Package (ESP) services for the poor, comprising child health, family planning, maternal health, communicable diseases and limited curative care of services.

Since most of the ESP services are preventive, it was believed that many clients would be willing to pay only a nominal fee for services. However, some clients indicated a willingness to pay for services if they were affordable. Donor agencies in Bangladesh have been asking NGOs to increase revenues by charging fees, while the Government of Bangladesh (GOB) does not allow NGOs not to charge fees for family planning methods, tetanus toxoid injections, BCG, DPT and polio immunizations in the EPI program. These conflicting forces threaten the financial sustainability of the NGOs as they seek to reduce donor dependency while complying with GOB directives to not charge for most preventive services.

Nevertheless, as a first step towards improving financial sustainability, PSTC increased the fees for some services for which the GOB would allow price increases. However, to increase cost recovery, it is essential that the price for each service is such that it yields a positive contribution margin, which is the difference between the revenue collected per client and the average variable cost of service provision. This represents the net revenue that can then be used to help offset the fixed costs of service provision. Only when the contribution margin is positive can the program hope to improve its financial sustainability through increased service provision.

In June 2006, therefore, PSTC undertook a demonstration project in two sites to assess the potential for improving financial sustainability by introducing higher service fees for selected services for which GOB would allow price increases. In Dhaka, the Rampura clinic is the largest and highest performing of PSTC's 15 clinics, serving about 65,000 persons in its catchment area. The Bashabo clinic serves about 42,000 persons in its catchment area. The interventions were expected to increase program revenues sufficiently to offset the increased costs associated with service provision as well as an increase in the volume of services provided. 


\section{OBJECTIVES}

The overall objective of the study was to improve the financial sustainability of two PSTC clinics. More specifically, the study attempted to test the feasibility of increasing cost recovery to 40 percent by:

1. Increasing the prices of frequently demanded services in order to yield a positive contribution margin per unit of service.

2. Promoting the increased provision of these services among existing clients within the existing staff structure of the program.

\section{Research Questions}

The research questions were:

1. What price is required to yield a positive contribution margin for frequently demanded services?

2. Are clients willing to pay a price for these services sufficient to yield a positive contribution margin?

3. Can the program provide enough of these services to obtain a 40 percent cost recovery ratio?

\section{METHODOLOGY}

A simple pre-post-test design was used to evaluate the feasibility of changing the service fees of frequently demanded services to raise cost recovery. A combination of primary data collection and secondary data analysis were used. The actual implementation of the study consisted of the following steps:

1. Analysis of costs

2. A willingness to pay survey

3. Changing the fees structure of the services

4. An in-reach marketing campaign

5. Collection of service-provision data before and after change in fees structure.

Analysis of Costs: Due to practical difficulties, collection of cost data could not be completed. Therefore, costs were estimated on the basis of a prior cost analysis of PSTC programs that was conducted for October 2003 - September 2004. Data from the 2003-04 cost analysis were adjusted to take into account inflation and changes in service volume.

Willingness to pay Survey: A convenience sample of 300 clients was recruited at each clinic. The respondents were asked to report on their willingness to pay a price increase for services that the client had just received. Questions were asked about 13 services. 
Changing the fee structure of the ESP: In January 2007, PSTC introduced a revised schedule of service fees at the two demonstration clinics. The decision as to the amount of increase in fees was arbitrary and different for the two clinics. For Rampura clinic, the fee for most services was increased from 30 taka $^{1}$ to 40 taka (a 33\% increase), and for measles vaccine from 20 taka to 35 taka (a 75\% increase). In the Bashabo clinic, the fee increased from 30 taka to 50 taka (a 66\% increase) and from 20 taka to 30 taka (a 50\% increase) for measles vaccination. These changes were implemented before the study began and were not based on the evidence that would be produced by the OR study.

Collection of service-provision and revenue generated data: The clinic registers were used to collect information on the volume of services provided and the revenues collected for three months both prior to and after the change in fees structure.

\section{IMPLEMENTATION PROBLEMS}

Although PSTC attempted to collect all the required information for conducting the OR study and analyzing the results, the study faced various limitations at different stages, which made it impossible to collect reliable data.

\section{Problems with the Cost Analysis:}

Discussions with PSTC revealed that the cost analysis could not be completed as planned. Therefore, it was decided that the results of a previous cost analysis would be used to estimate total costs. But PSTC failed to provide FRONTIERS staff with the full cost report, and so the study team was forced to rely on a summary table and adjust the results to account for general medical care inflation and changes in the size of operations. However the data required too many assumptions to be used in the study. Therefore, although service provision and revenue data were collected before and after price increases, they could not be used to calculate "cost-recovery" because of a lack of data on costs. Lack of cost data also made it impossible to estimate a contribution margin.

Problems with the WTP survey:

A total of 300 clients were to be interviewed about each of 13 services for the WTP survey. Interviews were conducted with fewer than 100 clients for most services, and no service reached the target of 300 interviews. Therefore the sample was inadequate to estimate WTP for any service and so the survey results were unusable for the study.

\section{Fees for Services Provided}

PSTC operates on the principle that, "No customer will be deprived from the services even if they fail to pay a service charge." Unfortunately, a comprehensive fee exclusion system was not in existence. Some clients had cards that allowed them to receive services for free. Others could receive free or reduced price services simply by telling the provider that they could not pay._Due to the existence of uncontrolled fees waivers, the whole idea of increasing cost recovery by increasing fees became very problematic. Unfortunately, the existence of the waiver system was

${ }^{1} 1 \mathrm{Taka}=0.0145$ US $\$$ 
not discovered until well into the study. Lack of awareness of the waiver system also prevented research into the key sustainability problem - can the exoneration system be changed?

\section{Marketing campaign:}

No information was received from PSTC about a marketing campaign to promote the services.

The above problems were made worse by frequent staff turnover at PSTC and FRONTIERS. The PSTC study was for a 12 month period; in this time, three research officers were hired and left PSTC and there was staff turnover of economists providing technical assistance at both the Population Council's India office and at FHI.

\section{LESSONS LEARNED}

While similar projects in Nepal and India were implemented smoothly, the Bangladesh study could not be implemented. Important lessons learned for future capacity building projects include:

- Selection criteria for NGOs wishing to participate in sustainability studies should include some research experience. PSTC, an NGO with no background in research, needed much more TA than it was possible to give or that was contemplated at the design stage of the project. Top management must demonstrate interest in cost recovery and sustainability.

- Donors or governments have not put restrictions on NGO cost recovery activities.

- For service delivery NGOs, it is difficult to attract or retain research professionals for short duration studies, resulting in frequent turnover that makes project implementation difficult. 